Caracterização sócio-econômica do trabalhador temporário da indústria canavieira em Lagoa da Prata, Minas Gerais, Brasil Maria Regina Alves Maciel, Alysson Rodrigo Fonseca, Francisco Assis Braga, Batistina Maria de Souza Corgozinho,

\title{
CARACTERIZAÇÃO SÓCIO-ECONÔMICA DO TRABALHADOR TEMPORÁRIO DA INDÚSTRIA CANAVIEIRA EM LAGOA DA PRATA, MINAS GERAIS, BRASIL
}

\section{Socioeconomic Characterization of the temporary worker of the sugar-cane industry in Lagoa da Prata, Minas Gerais, Brazil}

Maria Regina Alves Maciel

Socióloga, Mestre em Educação, Cultura e Organizações Sociais, Departamento de Pós-graduação da Funedi.

Divinópolis/MG - Brasil mregina_maciel@yahoo.com.br

Alysson Rodrigo Fonseca

Eng. Agrônomo, D.S Ciências, Centro de Pesquisa da Funedi.

Divinópolis/MG - Brasil arodrigofonseca@hotmail.com

Francisco Assis Braga Doutor em Ciência Florestal - UFV. Professor adjunto na Universidade Federal de Viçosa. Divinópolis/MG - Brasil francisco.braga@ufv.br

Batistina Maria de Souza Corgozinho Socióloga, Doutora em Educação pela Universidade Federal de Minas Gerais - UFMG. Centro de Memória da Funedi.

Divinópolis/MG - Brasil bcorgozinho@funedi.edu.br

Artigo recebido para publicação em 07/04/2011 e aceito para publicação em 02/08/2011.

RESUMO: $\quad$ A indústria sucroalcooleira, nos moldes que se apresenta na atualidade brasileira, implica na geração de impactos econômicos, ambientais e sociais. Nesse último ressalta-se a geração de empregos e a constituição do profissional temporário, o cortador de cana. A pesquisa teve como objetivo caracterizar algumas variáveis sócio-econômicas relativas ao trabalhador temporário da agroindústria canavieira de Lagoa da Prata, Minas Gerais. O trabalho buscou, mediante uma pesquisa documental exploratória de natureza quantitativa e descritiva, caracterizar o perfil sócio-econômico dos trabalhadores temporários da agroindústria canavieira de Lagoa da Prata - MG. Os resultados indicam que a maioria dos trabalhadores temporários do setor sucroalcooleiro são migrantes, homens e jovens, com ensino fundamental incompleto, sendo a maioria não sindicalizado. A presença majoritária de jovens evidencia a correlação entre a disposição física e a força muscular exigida pelo trabalho proposto. A maioria sendo migrantes sazonais pode ser explicada pela inibição dos trabalhadores locais diante do baixo salário oferecido, associados ao trabalho pesado e desgastante do corte da cana. A priorização do trabalhador do sexo masculino em detrimento do sexo feminino se justificou pela superioridade biológica natural para o desempenho do trabalho e pela maior oferta de mão-de-obra.

Palavras-chave: Cana-de-açúcar. Trabalhador temporário. Saúde, Lagoa da Prata. 
ABSTRACT: The sugar and alcohol industry in the patterns which presents itself in the Brazilian reality has always produced great economic, environmental and social impacts, some of them identified only nowadays. In that sense, the constitution of the temporary worker, the cane cutter and generation of employments is stressed. The work conducted about these aspects was intended to characterize some socioeconomic variables relative to the temporary worker of the sugar cane industry which exists in the town of Lagoa da Prata/MG. Through a documental exploratory research work of quantitative and descriptive nature we seek to characterize the socioeconomic profile of those temporary works of the sugar cane agroindustry. The information which contributed towards the identification of that profile were obtained from the only sugar cane enterprise which acts in the town and in the record of the workers in the databank of the Lagoa da Prata rural workers'syndicate. The results point out that most of the temporary workers of the sugar alcohol sector is migrant, constituted mainly of young men com incomplete primary education and non-syndicalized. The majority presence of young people stands out the correlation between physical aptitude and the muscular strength demanded by cane-cutting. The greatest presence of the seasonal migrant worker and not of the local worker is related to the low wage paid, associated to the work regarded as heavy and stressful That worker is chiefly of the male gender for being the majority of the labor offered and for being regarded as carrier of better physical conditions for the doing of the demanded work.

Keywords: Sugar cane, Temporary worker. Health, Lagoa da Prata.

\section{INTRODUÇÃO}

O cultivo da cana-de-açúcar (Saccharum sp) foi a primeira grande atividade produtiva instalada no Brasil, ainda no período da colonização portuguesa e, desde então, a dimensão territorial e os impactos sociais, ambientais e econômicos decorrentes dessa atividade foram crescendo junto com a expansão dos canaviais em direção a outras áreas e regiões. Atualmente, a demanda mundial crescente por energias renováveis, a competitividade do álcool como combustível e a aceitação dos usuários pelos veículos movidos a álcool têm incentivado cada vez mais a produção desse combustível. Portanto, a cultura ocupa na atualidade aproximadamente seis milhões de hectares das terras agricultáveis brasileiras, concentrada principalmente na região sudeste e nordeste, com cerca de oitocentos mil trabalhadores empregados diretamente, o que corresponde a aproximadamente 25\% da força de trabalho da agricultura (FERRAZ, 2008; GUIMARAES et al. 2010).

Em Minas Gerais, a atividade sucroalcooleira esteve, durante muitos anos, concentrada nas regiões da Zona da Mata e Sul. Após os anos 90, transferiu-se para a região do Triângulo Mineiro, principalmente, devido aos investimentos realizados pelos principais grupos empresariais nordestinos, atraídos pelas condições topográficas, o clima e a proximidade com São Paulo, seu maior produtor. Com isso, o Estado de Minas Gerais aumentou sua participação na produção de cana-de-açúcar brasileira. Esse crescimento vem sendo acompanhado por uma concentração maior de indústrias e monoculturas nas mesorregiões Noroeste de Minas, Central Mineira, Oeste de Minas, Triângulo Mineiro e Alto Paranaíba, suas principais regiões produtoras (SINDAÇÚCAR, 2003 SIQUEIRA; REIS, 2008 PEREIRA et al. 2010).

Paralelamente à geração de empregos e renda, essa produção tem provocado relevantes impactos sociais, principalmente no que se refere à questão dos trabalhadores informais, geralmente migrantes originários do nordeste do Brasil. Na região centro-oeste do Estado de Minas Gerais, o Município de Lagoa da Prata apresenta-se como um importante pólo de produção sucroalcooleira, necessitando anualmente de grande quantidade de trabalhadores rurais temporários que são admitidos e demitidos todos os anos. Ressalta-se que, segundo Brasil (1986), na classificação "trabalhador rural" são distintas duas categorias: 
o trabalhador direto protegido pela Consolidação das Leis Trabalhistas (CLT), que é aquele contratado por tempo indeterminado ou definitivo e o trabalhador rurícola braçal, contratado em regime temporário para um período de um ano para cumprir tarefas variadas em um período de safra. Essas tarefas referem-se ao corte de cana, plantio, colheita, aspersão de agrotóxicos, aspersão de vinhaça, ajudantes gerais, excluindo os trabalhos da moenda e engenho, assim como serviços de escritórios e almoxarifados que são atribuídos aos trabalhadores diretos. Caso as atividades da safra terminem antes deste tempo de um ano, automaticamente o contrato é rescendido e o trabalhador temporário pode ser demitido a qualquer momento.

De acordo com dados do IBGE (2010), fenômeno de êxodo rural também tem sido constato no município de Lagoa da Prata. Em função da ocupação das terras pelo plantio de cana e pela absorção da mão-de-obra dos trabalhadores rurais pela indústria de açúcar e álcool, muitos deixaram a zona rural para residirem na zona urbana, atraídos pelas melhores condições de trabalho e de vida almejadas na cidade. Observa-se, portanto, um aumento acelerado da população urbana no município e conseqüente uma diminuição da população rural (IBGE, 2008).

Vários estudos desenvolvidos no Brasil e especialmente em São Paulo (ALESSI; NAVARRO, 1997; SCOPINHO et al., 1999; ALVES, 2006; NOVAES, 2007; RUMIN; SCHMIDT, 2008; RIBEIRO; FICARELLI, 2010; ROCHA et al., 2010) têm discutido a questão social e ambiental relacionada aos trabalhadores da cana de açúcar, porém, em Minas Gerais, pesquisas dessa natureza são ainda incipientes. Entretanto, independente do local onde são produzidos esses estudos os autores são unânimes em apontar aspectos como a baixa remuneração, carência de organização sindical, a exploração do trabalhador através do ganho por produtividade, as condições precárias de moradia e alimentação e, ainda, as condições ambientais rigorosas a que esses trabalhadores encontram-se expostos, impactando diretamente sua saúde e qualidade de vida.

Tendo em vista a importância da produção sucroalcooleira no Município de Lagoa da Prata - MG e especificamente, o trabalhador temporário que nela atua, buscou-se mediante uma pesquisa documental exploratória de natureza quantitativa caracterizar o perfil sócio-econômico desses trabalhadores, visto sua relevância social e econômica, assim como, a escassez de trabalhos nessa região.

\section{MATERIAL E METODOS}

O Município de Lagoa da Prata está localizado na região Centro-Oeste de Minas Gerais, no Alto São Francisco, com área de $442 \mathrm{~km}^{2}$ e cerca e 46.000 habitantes, a $211 \mathrm{~km}$ da capital Belo Horizonte. Sua economia é baseada na agropecuária voltada principalmente para laticínios, usina de açúcar e hoje é, também, um polo de fabrição de bichos de pelúcia. As áreas rurais periféricas da cidade estão atualmente ocupadas pela monucultura da cana-de-açúcar, na maioria das vezes em terrenos arrendados de antigos produtores rurais. Atualmente conta com uma área de 30.000 hectares de cana-de-açúcar cultivada e $70 \%$ de sua colheita já ocorrem com a utilização de máquinas.

Através de uma pesquisa documental exploratória de natureza quantitativa e descritiva, buscou-se caracterizar o perfil sócio-econômico dos trabalhadores temporários da agroindústria canavieira de Lagoa da Prata - MG. As informações relativas ao perfil sócio-econômico foram obtidas junto à única empresa canavieira que atua no município e ao cadastro dos trabalhadores existente no banco de dados do Sindicato dos Trabalhadores Rurais de Lagoa da Prata, totalizando 761 indivíduos que estavam atuando na safra do período do estudo, ou seja, de 25 de maio a 10 de junho de 2010. Os dados obtidos foram organizados em gráficos e tabelas e tratados através do processo de estatística descritiva.

Por se tratar de uma pesquisa que envolve diretamente seres humanos (Resolução 196/96 CNS), o projeto foi encaminhado para o Comitê de Ética da FUNEDI, obtendo aprovação em 04/06/2009, através do Parecer 51/2009.

\section{RESULTADOS E DISCUSSÃO}

Dos 761 trabalhadores, apenas $33(4,3 \%)$ eram mulheres, cuja média de idade estava em torno de 35 anos e 728 (95,7\%) homens cuja média de idade estava em torno de 33 anos. Segundo Cyrino (2009), Ribeiro 
e Ficarelli (2010), como o pagamento desses trabalhadores é definido pela quantidade de cana cortada os homens conseguem salários até o dobro maiores do que o das mulheres devido à força física que esse trabalho exige. Por esse motivo, há menor quantidade de mulheres interessadas e algumas só trabalham poucos meses do ano, ou então não trabalham para cuidar da casa e dos filhos.

A faixa de idade dos trabalhadores temporários encontra-se na Figura 1. Os dados demonstram maior número de trabalhadores no intervalo de 18 a 25 anos, com 297 trabalhadores, representando 38\% do total. No intervalo compreendido pela faixa etária de 26 a 30 anos, observou-se 158 trabalhadores $(21 \%$ do total). Essas duas faixas etárias compreendem juntas $59 \%$ dos trabalhadores, evidenciando que indivíduos mais jovens são os mais aceitos, especialmente devido ao fato deles se encontrem na plenitude do seu vigor físico, estando portanto, mais aptos para o trabalho de corte da cana, irrigação e adubação, dentre outras atividades que demandam força e resistência.

Figura 1: Faixa etária dos trabalhadores temporários da indústria açucareira em Lagoa da Prata - MG, junho de 2010.

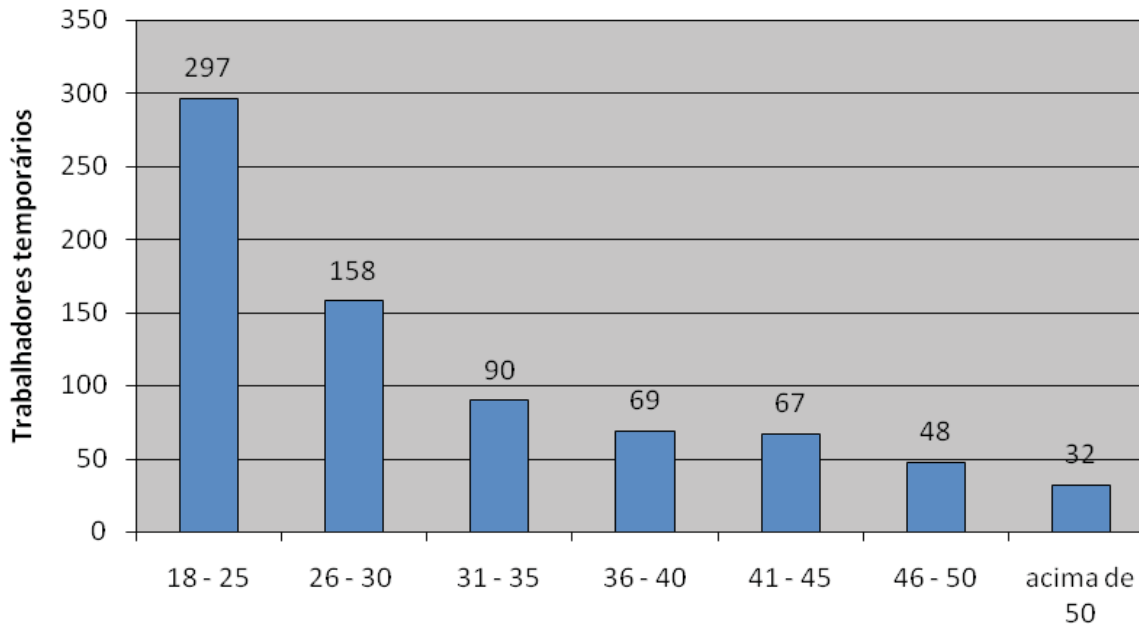

Idade em anos

No contexto da colheita da cana, chama-se a atenção ao fato do pagamento auferido pelos trabalhadores ser decorrente de sua produção, ou seja, quanto maior a produção mais eles recebem. Portanto, o trabalhador, quando recebe por produção, tem o seu pagamento atrelado ao que ele conseguiu produzir no dia. Como eles trabalham pela subsistência, trabalham cada vez mais para melhorar suas condições de vida e consequentemente provocam o aumento do ritmo de trabalho, transferindo ao trabalhador a responsabilidade de seu ganho (ALVES, 2006). De acordo com a CPT (2008) para um trabalhador cortar 12 toneladas de cana diariamente ele caminha cerca de 8.800 metros; despende 133.332 golpes de podão e carrega 12 toneladas de cana em montes, com peso médio de 15 $\mathrm{kg}$ cada. Para isso, realiza cerca de 800 trajetos e 800 flexões, levando $15 \mathrm{~kg}$ de cana nos braços por uma distância de 1,5 a 3 metros, com aproximadamente 36.630 flexões e entorses torácicos para golpear a cana, perdendo, em média, 8 litros de água.

Neste contexto, as condições de trabalho expõem os trabalhadores a exigências posturais e de dispêndio de força muscular excessivas em razão do acionamento mecânico de equipamentos e da utilização de instrumentos de trabalho. As dificuldades geradas para o controle dos equipamentos, além de ocasionar irritabilidade e lesões musculares, proporcionam riscos de acidentes por exigir do trabalhador adaptações dos sistemas de acionamento configurando-se potencialmente como risco (RUMIN; SCHMIDT, 2008). Aliado a isso, os indivíduos mais velhos, como esgotaram sua capacidade física de produção no volume esperado, acabam excluídos do processo de trabalho de forma direta ou indireta. Assim, como são 
trabalhadores temporários, sem garantias trabalhistas, muitos enfrentam inúmeras situações de penúria.

Entretanto, alguns avanços podem ser constatados. A empresa atualmente não emprega menores de 18 anos para execução de quaisquer tipos de tarefas, diferente do que ocorria no passado, em que crianças de 12 anos eram contratadas para serviços agrícolas, inclusive para o corte de cana. Balsadi (2008) relata que diante dos vários acordos coletivos de trabalho firmados entre empregados e patrões no setor canavieiro, normatizaram o trabalho por produção alcançando significativas melhorias em diversos indicadores sócio-econômicos ao longo do tempo, sendo a redução do trabalho infantil uma delas.

A tabela 1 caracteriza os trabalhadores, homens e mulheres, quanto a situação de contratação, atuação na empresa (setores de trabalho) e o número de migrantes e não migrantes. Quanto ao número de homens e de mulheres que atuavam nos setores de trabalho temporário observou-se que 18 mulheres estavam desempenhando trabalhos agrícolas (corte de cana, capina, plantio, irrigação), enquanto que para desempenhar o mesmo trabalho foram contratados 490 homens. Para desempenhar atividades na área da indústria (ajudantes na moenda, caldeira e outros), havia 87 homens e 14 mulheres, sendo que nos demais setores que não envolviam diretamente o corte de cana trabalhavam 151 homens e uma mulher.

Ainda segundo a Tabela 1, dentre os trabalhadores temporários, 608 eram homens e migrantes, o que corresponde a $80 \%$ do total de trabalhadores temporários $(\mathrm{n}=761)$. Na atual legislação trabalhista, os migrantes são contratados pela Instrução Normativa $\mathrm{N}^{\circ} 65$ de 19 de julho de 2006 (BRASIL, 2010), que dispõe sobre os procedimentos para a contratação de trabalhadores temporários migrantes, inclusive contratos que disciplinem a duração do trabalho, o salário, condições de alojamento, alimentação e de retorno à localidade de origem do trabalhador.

Tabela 1: Caracterização dos trabalhadores temporários da indústria açucareira em Lagoa da Prata - MG, safra de 2010.

\begin{tabular}{cccc}
\hline Trabalhadores & Homens & Mulheres & Total (100\%) \\
\hline Contratados & $728(95,7 \%)$ & $33(4,3 \%)$ & 761 \\
Atua no setor da indústria & $87(86,1 \%)$ & $14(13,9)$ & 101 \\
Atua no setor agrícola & $490(96,5 \%)$ & $18(3,5 \%)$ & 508 \\
Atua em outros setores & $151(99,3 \%)$ & $1(0,7 \%)$ & 152 \\
Migrantes & $608(100 \%)$ & $0(0,0 \%)$ & 608 \\
Não - migrantes & $120(78,4 \%)$ & $33(21,6 \%)$ & 153 \\
\hline
\end{tabular}

Fonte: Sindicato dos Trabalhadores Rurais de Lagoa da Prata - MG

Apesar da forma de pagamento por produtividade da colheita da cana-de-açúcar ser alvo de discussões, no mercado de trabalho sucroalcooleiro, a remuneração por produção tem ampla base legal. Ela está prevista no artigo 457, $\S 1^{0}$ da Consolidação das Leis do Trabalho (CLT), com incontroversa aceitação doutrinária e jurisprudencial. Da mesma forma, é prevista em normas coletivas de trabalho, para diversas culturas agrícolas. A limitação existente é que conforme o Artigo 78 da CLT deve ser garantido ao trabalhador um ganho mensal nunca inferior ao salário mínimo vigente (MORAES, 2007).
A pesquisa mostrou ainda que do total de 608 migrantes, um montante de 182 (30\%) trabalhadores eram provenientes de reservas indígenas do norte de $\mathrm{Mi}$ nas Gerais e 304 (50\%) eram nordestinos provenientes da região sul do estado da Bahia, mais especificamente de Morrinhos e áreas rurais vizinhas. Os demais pertenciam a cidades próximas a Lagoa da Prata ou mesmo outros Estados brasileiros. Para Zoratto (2009), a maioria dos trabalhadores "bóias-frias", em seu imaginário, acredita que vai conseguir melhores condições de vida para seus familiares, vendo em outro lugar maiores chances de melhorara em seu padrão de vida. 
De acordo com Novaes (2007), os trabalhadores que chegam do Nordeste possuem um perfil condizente com o que se precisa hoje para o corte manual. Por terem sido, desde crianças, socializados no árduo e duro trabalho da agricultura na sua região de origem, o trabalho no canavial não os assusta. Além disso, segundo relato dos técnicos das usinas eles são preferidos pelos usineiros por serem mais dedicados ao trabalho e gratos aos empregadores pela oportunidade do emprego, geralmente inexistentes em suas regiões.

Estudos como os de Silva (2001) e Martine (2007) têm demonstrado o lado negativo dos movimentos migratórios sazonais que terminam em migração convencional, uma vez que o migrante geralmente não retorna ao seu lugar de origem. Nesse sentido, Martine (2007) chama a atenção para o impacto social e ambiental negativo que se configura no momento em que populações migrantes, sem teto, ocupam áreas de ocupação predatória nas cidades de destino. Portanto, torna-se importante o planejamento do uso do solo urbano, por meio de políticas públicas que regularizem a ocupação dos imóveis no sentido de atender às necessidades dos pobres e evitar a ocupação predatória.

Verificou-se a inexistência de mulheres migrantes sazonais sendo trazidas e contratadas. As poucas mulheres que atuam nas atividades agrícolas, como o corte de cana ou catação de bitucas residiam no próprio município ou em cidades vizinhas, cabendo ressaltar que os trabalhadores temporários de cidades vizinhas que trabalham na usina e retornam para suas casas após o dia de trabalho não são caracterizados como migrantes sazonais, mas como migrantes pendulares. Zoratto (2009) afirma que é comum trabalhadores temporários trazerem suas famílias para a região na qual exercerão suas atividades sazonais, sendo que, na maioria das vezes, as esposas procuram serviços domésticos nas cidades ou mesmo atuam como bóias-frias. Nesse caso, por não atenderem a produtividade necessária, são geralmente empregadas para as tarefas ditas como mais simples, mas que demandam esforço repetitivo e desgastante, como as de bituqueiras, que recolhem restos de cana que as máquinas não conseguem colher.

Segundo Ribeiro e Ficarelli (2010) como os trabalhadores sazonais recebem de acordo com o que cortam, os homens conseguem salários até o dobro maiores do que o das mulheres, devido à força física que esse trabalho exige. Por esse motivo, há menos mulheres interessadas e algumas só trabalham poucos meses do ano, ou então não trabalham para cuidar da casa e dos filhos. Cyrino (2009) complementa apontando que a duplicidade de responsabilidade e a conseqüente aceleração de ritmos e cadências vivenciadas por mulheres que procuram manter-se no mercado de trabalho sem romper com seus antigos afazeres domésticos, funções tradicionais que as mulheres exercem secularmente e que permanecem como encargos específicos femininos, têm um caráter de invisibilidade social, sendo desqualificadas e desvalorizadas socialmente.

Do total de 761 trabalhadores que fizeram parte do estudo, 457 (60\%) já haviam sido admitidos de safras anteriores. A maioria desses trabalhadores $(n=609,80 \%)$ contava apenas com ensino fundamental incompleto e os demais com ensino médio concluído $(\mathrm{n}=152,20 \%)$. Além disso, 457 trabalhadores temporários, ou seja, $60 \%$ residia em casa própria, sendo que neste percentual incluímos os migrantes, que afirmaram viver em casa própria em suas cidades. Quanto aos indígenas, segundo a empresa e o Sindicato dos Trabalhadores Rurais, também possuíam moradia própria na reserva da FUNAI (Fundação Nacional do Índio), para onde retornariam logo que finalizasse o período de safra da cana. Por esse motivo foram considerados migrantes sazonais.

No que se refere às condições de vida, emprego e escolaridade no contexto da agroindústria canavieira, Bonacelli et al. (2003) chama atenção ao fato de que as relações tem se transformado ao longo do tempo, especialmente no que se refere ao número de vagas oferecidas em postos de trabalho; o tipo de vínculo e forma como se estabelecem as relações entre trabalhadores fixos e temporários; as exigências em relação ao nível de escolaridade e por fim, a remuneração dos trabalhadores, tanto em termos de salário como em termos de benefícios. Na sazonalidade, característica intrínseca das agroindústrias de cana-de-açúcar, as condições de emprego são alteradas pelo número variável de meses de trabalho por ano. Neste contexto, um fator preponderante de impacto na agroindústria sucroalcooleira sobre o trabalhador temporário é a tendência de mecanização da colheita, principalmente 
na região Centro-Sul, que é irreversível e tende a se acelerar. As usinas estão investindo em co-geração de energia elétrica a partir da queima de bagaço de cana, a palha também pode ser utilizada como matéria-prima para a co-geração de energia elétrica, o que estimula as usinas a deixarem de queimá-la. Portanto, além dos fatores institucionais (a legislação proibindo a queima da cana-de-açúcar), a mecanização tende a se acelerar também em função do aumento de competitividade das usinas, principalmente com o uso de colheitadeiras com tecnologia que permita a colheita em terrenos com maior declividade.

A questão que emerge deste contexto é que a mecanização da colheita altera o perfil do empregado, que segundo Moraes (2007), cria oportunidades para tratoristas, motoristas, mecânicos, condutores de colheitadeiras, técnicos em eletrônica, dentre outros, e reduz, em maior proporção, a demanda dos empregados de baixa escolaridade, uma vez que grande parte dos trabalhadores da lavoura canavieira têm poucos anos de estudo. Dessa forma, surge a necessidade de alfabetização, qualificação e treinamento desta mão-de-obra para desempenho de atividades que exijam maior escolaridade. Entretanto, cabe ressaltar que o baixo nível de escolaridade desses trabalhadores ainda é uma realidade no quadro brasileiro, conforme indica estudo realizado por Cano e Vergínio (2008), que realizando uma investigação em uma usina localizada na região de Fernandópolis, São Paulo, observaram que nenhum trabalhador encontrava-se estudando e, dos cortadores de cana, $42,35 \%$ não concluíram o ensino fundamental básico. Constataram ainda que a maior parte dos cortadores com idade mais avançada se concentra nos níveis de baixa escolaridade, com uma porcentagem de $83,33 \%$ de trabalhadores com mais de 50 anos que não concluíram o ensino fundamental básico. Certamente, para o trabalho que essas pessoas exercem (cortadores de cana), o nível de escolaridade não é tão relevante, entretanto, deve-se considerar que o baixo nível de escolaridade, associado à idade avançada, provavelmente reduziria suas chances de re-inserção no mercado de trabalho.

Verificou-se pela pesquisa a existência de um baixo percentual de trabalhadores sindicalizados (7\%), reforçando o argumento de Balsadi e Silva (2008), no qual o processo de modernização e mecanização ocor- rido na agricultura em grande escala, na atualidade, geralmente emprega poucos trabalhadores qualificados, sendo a maioria com baixa qualificação e fraca representação e organização sindical. Ainda, segundo os mesmos autores, a formação e a estruturação dos sindicatos de trabalhadores agrícolas assalariados é muito importante para o fortalecimento de todas as categorias na agricultura. Mesmo que os empregados permanentes estejam em situação consideravelmente mais favorável, especialmente no que se refere às condições de trabalho e rendimentos, torna-se preciso admitir que, ainda, são necessárias políticas públicas e muitas ações dos trabalhadores e dos agricultores no sentido de proporcionar melhores condições de trabalho para os empregados temporários, os quais vivem um nível elevado de precarização.

A caracterização geral dos trabalhadores temporários nos permite vislumbrar aspectos da sua qualidade de vida que, para Bonacelli et al. (2003), é o reflexo das mudanças gerais no seu cotidiano, nem sempre relacionadas com seu ambiente de trabalho. Portanto, conforme Silva et al. (2002) e Souza et al. (2010), torna-se necessário o entendimento de que as políticas e ações protetoras direcionadas ao trabalhador devem proporcionar benefícios a todos os envolvidos na relação de trabalho e que esse fator não deve ser visto apenas através da visão econômica, mas principalmente, como uma questão de características humanas e sociais.

\section{CONCLUSÃO}

A maioria dos trabalhadores temporários do setor sucroalcooleiro atuantes em Lagoa da Prata MG, eram migrantes homens e jovens, mostrando a correlação entre a disposição física e a força muscular exigida para esse tipo de labor. A maioria das vagas é preenchida pelos migrantes sazonais, especialmente devido ao baixo salário oferecido associado ao trabalho pesado e desgastante dos tratos e colheita da cana, onde muitos dos trabalhadores locais, com melhores chances no mercado de trabalho paralelo, acabam por refutar.

A priorização do trabalhador do sexo masculino em detrimento do sexo feminino certamente se justifica pela maior força física que, geralmente, os 
homens desenvolvem mais que as mulheres e ainda, pela maior oferta de mão-de-obra.

Os trabalhadores temporários da cana-de-açúcar são fracamente organizados. Apenas uma pequena porcentagem participa de sindicato, que a princípio seria o meio mais seguro para conquistas de melhorias salariais.

Em função dos resultados obtidos torna-se necessário exercitar a reflexão e crítica frente a atual situação do trabalhador temporário e as políticas que reguem esse sistema. Os aspectos observados nesta pesquisa refletem de modo específico, as mudanças gerais ocorridas na região em função das transformações do Município de Lagoa da Prata - MG em sua trajetória de desenvolvimento e mesmo da usina sucroalcooleira, com as mudanças internas vividas, desde sua implantação na década de 1950. A qualidade de vida e o perfil dos trabalhadores temporários refletem as mudanças que ocorrem em seus valores, conferindo identidade à população do município, especialmente no que se refere aos aspectos sócio-culturais e econômicos.

\section{REFERÊNCIAS}

ALESSI, N. P.; NAVARRO, V. L. Saúde e trabalho rural: o caso dos trabalhadores da cultura canavieira na região de Ribeirão Preto, São Paulo, Brasil. Cadernos de Saúde Pública, v. 13, supl. 2, p.111-121, 1997.

ALVES, F. Por que morrem os cortadores de cana? Saúde e Sociedade, v. 15, n. 3, p. 90-98, 2006.

BALSADI, O. V; GRAZIANO DA SILVA, J. F. A polarização da qualidade do emprego na agricultura brasileira no período 1992-2004. Revista Economia e Sociedade, v. 17, n. 3, p. 493-524, 2008.

BALSADI, O. O mercado de trabalho assalariado na cultura da cana-de-açúcar. Dossie Ethanol. Revista Eletrônica da SBPC, n. 86. Disponível em: <http://www. comciencia.br/comciencia>. Acesso em: 10 abr. 2008.

BONACELLI, M. B. M.; BIN. A; ZACKIEWICZ, M. Avaliação de impactos sociais de programas tecnológicos na agricultura do estado de São Paulo. Espacios, v. 24, n. 2 , p. 142-153, 2003.
BRASIL, Leis, decretos etc. Consolidação das leis do trabalho/ .In: Oliveira, j. (Org.). ed. rev. e aum. São Paulo: Saraiva, 1986.

BRASIL, Ministério do Trabalho e Emprego. Disponível em: < http://www.mte.gov.br/legislacao/ normas_regulamentaDORAS/nr_31.pdf.>. Acesso em: 13 mar. 2010.

CANO, A.; VERGÍNIO, C. Impactos da mecanização da colheita da cana no período de 2001 a 2006: estudo de caso de uma unidade produtora em Fernandópolis, SP. Scientia FAER, v. 2, p. 1-15, 2010.

CYRINO, R. Trabalho, temporalidade e representações sociais de gênero: uma análise da articulação entre trabalho doméstico e assalariado. Revista Sociologias, n. 21, p. 66-92, 2009.

COMISSÃO PASTORAL DA TERRA - CPT. O Brasil dos Agrocombustíveis: impactos das Lavouras sobre a Terra, o Meio e a Sociedade - Cana-de-açúcar. Disponível em: <http://www.reporterbrasil.org.br/ agrocombustiveis $>$. Acesso em: 05 jul. 2009.

FERRAZ, J. M. G.; PRADA, L. S.; PAIXÃO, M. Certificação Socioambiental do setor Sucroalcooleiro. São Paulo: Embrapa Meio Ambiente, 2000. 195 p.

GUIMARAES, L.T.; TURETTA, A.P.D.; COUTINHO, H.L.C. Uma proposta para avaliar a sustentabilidade da expansão do cultivo da cana-de-açúcar no estado do Mato Grosso do Sul. Sociedade \& Natureza [online], v. 22, n. 2, p. 313-327, 2010.

MARTINE, G. O lugar do espaço na equação população/meio ambiente. Revista Brasileira de Estudos Populacionais, v. 24, n. 2, p. 181-190, 2007.

MORAES, M. A. F. D. O mercado de trabalho da agroindústria canavieira: desafios e oportunidades. Economia Aplicada, v. 11, n. 4, p. 605-619, 2007.

NOVAES, J. R. P. Campeões de produtividade: dores e febres nos canaviais paulistas. Estudos Avançados, v. 21, n. 59, p. 167-177, 2007. 
NUNES, F; P. O homeme, as matas ciliares e os peixes de Lagoa da Prata, no Alto São Francisco. um estudo das intervenções. 2005. 56f. Dissertação. PUC-MG, Belo Horizonte, 2005.

PEREIRA J. R., et al. O zoneamento da cana-de-açúcar e do eucalípto condicionantes socioeconônicos e índice de monocultura. Disponivel em: $<\mathrm{http}>/ / \mathrm{www}$. zee.mg.gov.br>. acesso em 15 de agosto de 2010

RIBEIRO, H.; FICARELLI, T. R. A. Queimadas nos canaviais e perspectivas dos cortadores de cana-de-açúcar em Macatuba, São Paulo. Saúde e Sociedade, v. 19, n. 1, p. 48-63, 2010.

ROCHA, F. L. R.; MARZIALE, M. H. P.; HONG, O. Work and health conditions of sugar cane workers in Brazil. Revista da Escola de Enfermagem da USP, v. 44, n. 4, p. 978-983, 2010.

RUMIN, C. R.; SCHMIDT, M. L. G. Influências das condições e organização do trabalho de uma indústria de transformação de cana-de-açúcar na ocorrência de acidentes de trabalho. Saúde e Sociedade, v. 17, n. 4, p. 56-67. 2008.

SOUZA, A. P.; VIANNA, H. A.; MINETTE, L. J.; MACHADO, C. C. Avaliação das condições de segurança no trabalho nos setores florestais de uma Instituição Federal de Ensino Superior. Revista Árvore, v. 34, n. 6, p. 1139-1145. 2010.

SILVA, M. A. M. A terra no imaginário dos migrantes temporários. Revista História Oral, n. 4, p.103-120, 2001.

SILVA, K. R.; SOUZA, A. P.; MINETTI, L. J. Avaliação do perfil de trabalhadores e das condições de trabalho em marcenarias no município de Viçosa-MG. Revista Árvore, v. 26, n. 6, p. 769-775. 2002.

SINDICATO DA INDÚSTRIA DO AÇUCAR. Realidade e perspectivas do setor sucroalcooleiro de Minas com foco no desenvolvimento social e econômico. Minas Gerais: SINDAÇÚCAR, 2003. 20 p.

SCOPINHO, R. A.; EID, F.; VIAN, C. E. F.; SILVA, P. R. C. Novas tecnologias e saúde do trabalhador: a mecanização do corte da cana-de-açúcar. Cadernos de Saúde Pública, v.15, n.1, p. 147-162, 1999.

ZORATTO, A. C. Principais impactos da cana-de-açúcar. Disponível em: $\leq$ http://www.sucre-ethique. org/IMG/cache-150x101/BOIA-FRIA-daniellarosario7-150x101.jpg $>$ Acesso em: 18 set 2009. 